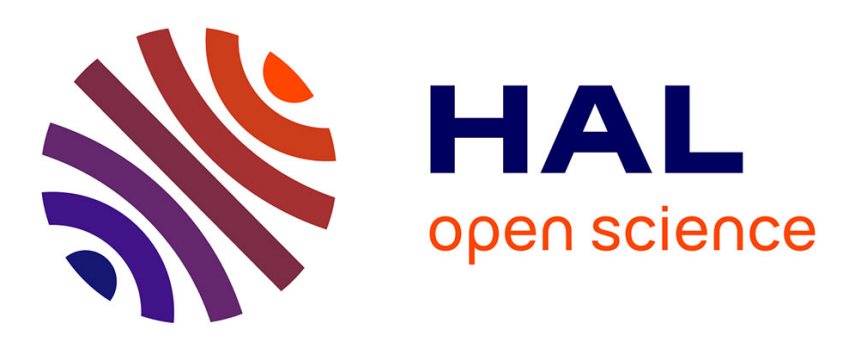

\title{
Fuel Cell System Improvement for Model-Based Diagnosis Analysis
}

Philippe Fiani, Michel Batteux, Philippe Dague, Nicolas Rapin

\section{To cite this version:}

Philippe Fiani, Michel Batteux, Philippe Dague, Nicolas Rapin. Fuel Cell System Improvement for Model-Based Diagnosis Analysis. Vehicle Power and Propulsion Conference IEEE VPPC, Sep 2010, Lille, France. inria-00540836

\section{HAL Id: inria-00540836 https://hal.inria.fr/inria-00540836}

Submitted on 29 Nov 2010

HAL is a multi-disciplinary open access archive for the deposit and dissemination of scientific research documents, whether they are published or not. The documents may come from teaching and research institutions in France or abroad, or from public or private research centers.
L'archive ouverte pluridisciplinaire HAL, est destinée au dépôt et à la diffusion de documents scientifiques de niveau recherche, publiés ou non, émanant des établissements d'enseignement et de recherche français ou étrangers, des laboratoires publics ou privés. 


\section{Fuel Cell System Improvement for Model-Based Diagnosis Analysis}

\author{
Philippe Fiani \& Michel Batteux \\ Sherpa Engineering \\ La Garenne Colombes, France \\ p.fiani@sherpa-eng.com \& \\ m.batteux@sherpa-eng.com
}

\author{
Philippe Dague \\ LRI IASI \& INRIA LEO \\ Univ. Paris-Sud $11 \&$ INRIA Saclay \\ Orsay, France \\ philippe.dague@1ri.fr
}

\author{
Nicolas Rapin \\ CEA LIST, Laboratory of Model driven \\ engineering for embedded systems, \\ Point Courier 94, Gif-sur-Yvette, \\ F-91191 France \\ nicolas.rapin@cea.fr
}

\begin{abstract}
This paper is concerned with the improvement of a model of a fuel cell system, in order to make it usable for modelbased diagnosis methods. A fuel cell system is a complex system with many components where faults can occur and cause hard damages not only for the fuel cell stack but also for the system environment. In this paper, we present an adapted library which integrates, directly in the fuel cell system model, all important faults identified and classified. This provides all models with faults required for model-based diagnosis methods.
\end{abstract}

Keywords-component: fuel cell modelisation, faults modelisation, model-based diagnosis, model-based diagnosability

\section{INTRODUCTION}

A fuel cell system (FCS) is a complex system with many components interacting with each other's and combining thermodynamic, hydraulic and electric phenomena. Faults, which are un-observable damages affecting components of the FCS, can occur due to many causes (wear, dirtying, breakage ...). Some are serious and must require to stop the system, or to put it in a safety mode: an hydrogen leakage which can lead to an explosion; while others have minor impact and should only be reported for being repaired off-board: a dirtying of a valve which reduces system performances.

In order to protect the system and its environment, but also to avoid useless stop of the system, it is necessary not only to achieve, on-board, the detection of those faults; but also to identify them the most precisely in order to take the appropriate decision. An embedded diagnosis system, completing the controller, is a suitable solution to do this. The problem is then: will this system always be able to detect any fault when it occurs (does the fault induce an observable behavior distinct from the normality?) and will this system be able to assign a unique listed fault to a divergent observable behavior (do some faults induce the same observable behavior?). This problem is known as the diagnosability problem.

A way to study diagnosability of faults with respect to a system is to improve the model of this system (the faultless model) with faults (faulty models); and then to exploit these models to study impact of fault activations on observable behaviors. This approach, called model-based diagnosability (MBDy), requires by definition all faulty models and produces, for each one, a specific fault characterization according to its observable behaviors. All these fault characterizations will then be used by the embedded diagnosis system to detect and identify faults with a model-based diagnosis (MBD) approach ([3] and [5] are full explanations of MBD methodology).

In this paper we propose an adapted library providing templates to improve models with many kinds of faults, which can be used in the context of MBDy study. In the second part, we present the FCSM and its controller. In the third part, we show how to improve, with the library, the FCSM with faults. In the fourth part, we show and analyze behaviors without and with faults and summarize how these behaviors can be used in the context of MBDy study. Finally in the last part, we conclude by summarizing the result and outline interesting directions for future works.

\section{THE FUEL CELL SYSTEM MODEL AND ITS CONTROLLER}

\section{A. The context of the fuel cell system}

During the FISYPAC project ([1]), which objective was to develop a reliable FCS and to test it on board an electric vehicle, a controller for the FCS was developed with a modelbased approach: by using a complete model of the FCS (a FCSM) to simulate its behaviors. This controller contains all different control's algorithms for the normal behavior of the FCS; but for all abnormal ones (just detected by threshold of sensors), the system is stopped, even with behaviors induced by minor faults.

\section{B. The fuel cell system}

In [1], a complete description of the FCS is given. It is a PEMFC technology which combines hydrogen and oxygen from air to produce power, water, and heat. These reactions must be carried out at a suitable temperature, pressure and humidity for fuel cell operation. It is composed by the fuel cell stack and its three lines: the hydrogen line and the air line to aliment the stack; the cooling line to ensure the temperature homogeneity in the stack. In this paper, we are only concerned with the fuel cell stack and its two alimentation lines (Fig. 1); 
and we don't completely present the system in more details but just explore it in order to point out all important components.

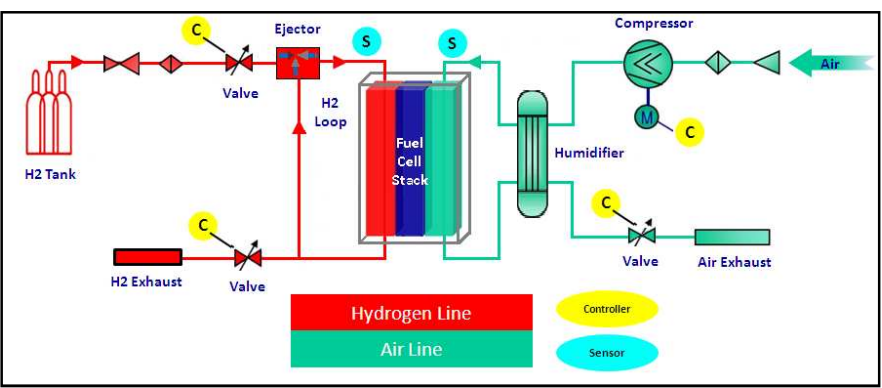

Figure 1: FCS organic architecture

The stack consists of two fuel cell modules, each one composed by 120 fuel cells, connected to a central fluid distributor which assures alimentation and cooling to the modules.

The air line aliments the stack with oxygen: a compressor controls the air mass flow rate and a modulating electric valve controls the air pressure. A humidifier, a physical component functioning like a sponge, controls the air humidity.

The hydrogen line aliments the stack with compressed hydrogen (700 bars) stored in a tank: a modulating electric valve controls the admission of hydrogen to the appropriate pressure in the line. An ejector, dimensioned especially to ensure the appropriate hydrogen stoichiometry and humidity, is used to ensure hydrogen recirculation. A modulating electric valve controls the hydrogen rejection.

\section{The model of the fuel cell system}

The FCSM was designed according to different works: [7], [8] and [9] for electrochemical models describing the relationship between cell current and voltage; [10], [11], [12] and [13] for dynamical models of fuel cell systems, taking into account all principal thermodynamic, hydraulic and electric phenomena. It was furthermore validated with the FCS during experimental validations.

The FCSM is developed in Matlab/Simulink@ by using a component-based approach given by PhiGraph $\odot$ and PhiSim $\odot$ tools ([17]). PhiGraph@), adapted from Bond-Graph concept, is a tool for programming models and libraries of physical systems by using a block diagram environment. PhiSim® is a tool extending PhiGraph@ by adding multi-port concept.

The FCSM represents static and dynamic behaviors of the system and is composed, as the real system, by three parts: the fuel cell stack and the two alimentation lines. It is composed with elementary blocs (compressor, ejector, valves, humidifier, fuel cell stack, etc) used as base pieces in the model according to physical phenomena (mass flow rate, pressures, humidity rate, stoichiometries, temperature, electric tension, etc) to be considered. Fig 2 shows the air line model of the FCSM: it is composed with the compressor, the valve, the humidifier, two gas sources to represent air admission and exhaust; and four gas volumes to represent pipes between all components.

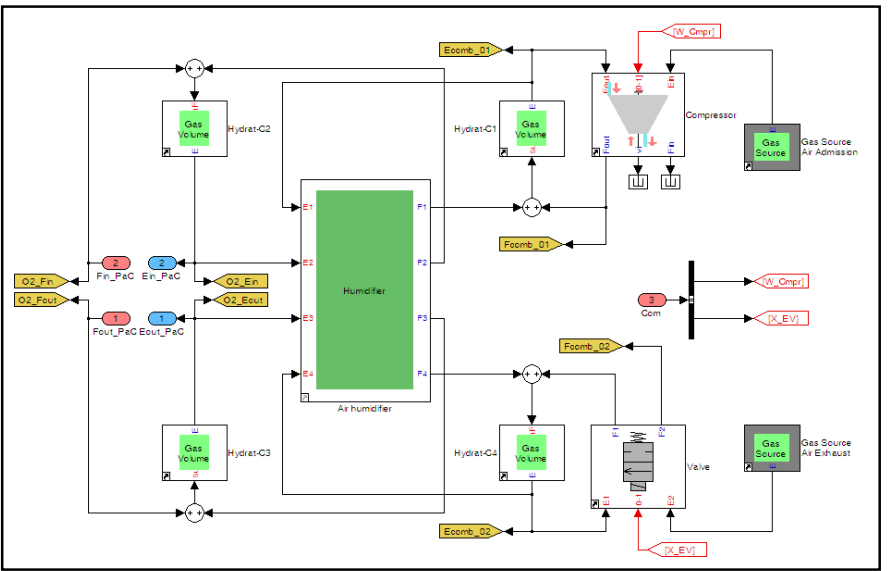

Figure 2 : air line model of the FCSM

Fig. 3 shows a comparison between real and model data realized during an experimental validation. The first graph shows the electrical power ordered by the FCS controller (red dot line) and measured from the FCS (blue plain line). The other graphs show respectively the stack temperature, the air pressure and the air mass flow rate; measured from the FCS (blue plain line) and given from the model (red dot line).

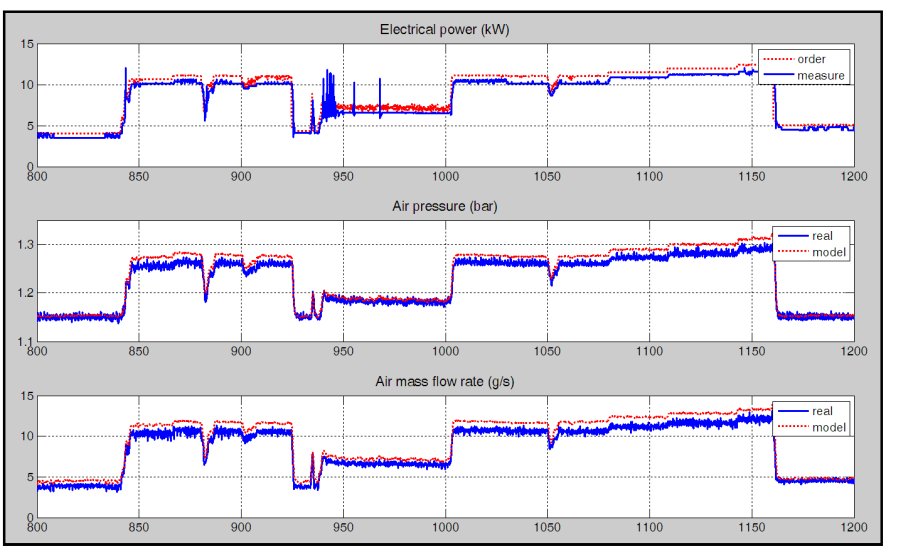

Figure 3 : comparison between real and model data

\section{The controller of the fuel cell system}

The controller of the FCS was designed and developed with a model-based approach by using a model-based predictive functional control. Its structure reproduces the hierarchical decomposition of the system by decomposing it as a dual structure of the system: a global controller for the FCS and two sub controllers for each line.

The global FCS controller computes the air mass flow rate and the air and hydrogen pressures. The air mass flow rate is computed according to the electrical power needed by the vehicle controller and the stoichiometry requirement (limited to 1.5). The air pressure is then deduced from the air mass flow rate according to pressure requirements in the stack (between 1.3 and 1.5 bars). Furthermore, the hydrogen pressure is computed in order to follow the air pressure (the pressure gradient between anode and cathode must be less than 300 mbar): by following directly the air pressure measure.

The air line controller computes compressor and valve orders according to the air mass flow rate and the air pressure 
needed. The hydrogen line controller computes valves' orders according to the hydrogen pressure needed.

There is a feedback between all controller levels: the vehicle controller, the FCS controller and the air and hydrogen line controllers. When the vehicle controller requests an electrical power to the FCS controller, this one (the FCS controller) computes the mass flow rate and pressures needed and requests them to air and hydrogen line controllers. Then they regulate their own lines and inform the FCS controller to mass flow rate and pressures produced; the FCS controller estimates the electrical power produced and informs the vehicle controller.

\section{IMPROVEMENT OF THE FUEL CELL SYSTEM MODEL}

To improve the fuel cell model by faults, it is important to know which faults are important and how to integrate them in the model.

\section{A. Indentification of important faults}

As say before, faults in the FCS can cause failures or malfunctions, resulting in serious damage not only to the fuel cell stack but also to the FCS environment. As example, [17] shows that hydrogen characteristic (a small molecule and a great propensity to escape through small openings) make it suitable to leak, which can lead to an explosion; in [14], [15] and [16] the hydrogen leak fault detection is studied with a MBD approach.

By using the RAMS (Reliability, Availability, Maintainability and Safety) methodology ([2] and [3]), an identification of all important faults of the system can be made. For our interest, we are focused with important faults concerned with the integrity of the fuel cell stack and the risk with hydrogen use. Sensor and actuator faults are the majority ones, but we have added some faults in physical components (leak of hydrogen or drying out of the humidifier) because of theirs relations with the integrity of the fuel cell stack or the risk with hydrogen use.

The fault case study for this paper is a lock of the air compressor. This fault can cause damages to the fuel cell stack because when the air compressor is locked, the stack is not alimented with oxygen and the differential pressures between air and hydrogen must be high. This fault is represented by an abruptly and highly decreasing of the mass flow rate and pressure in the air line.

\section{B. Fault classification}

Various classifications of fault can be found in literature. But all of them differentiate the behavior of the fault and its effects in the system.

\section{1) Fault behaviors}

In [3] and [6], different fault behaviors can be distinguished. The time apparition differentiates faults which occur randomly, at a specific time or from a specific event. The appearance differentiates faults which occur abruptly or progressively. The form differentiates permanent faults, transient faults and intermittent faults. This is the fault behavior, which characterizes the time apparition, the appearance and the form.

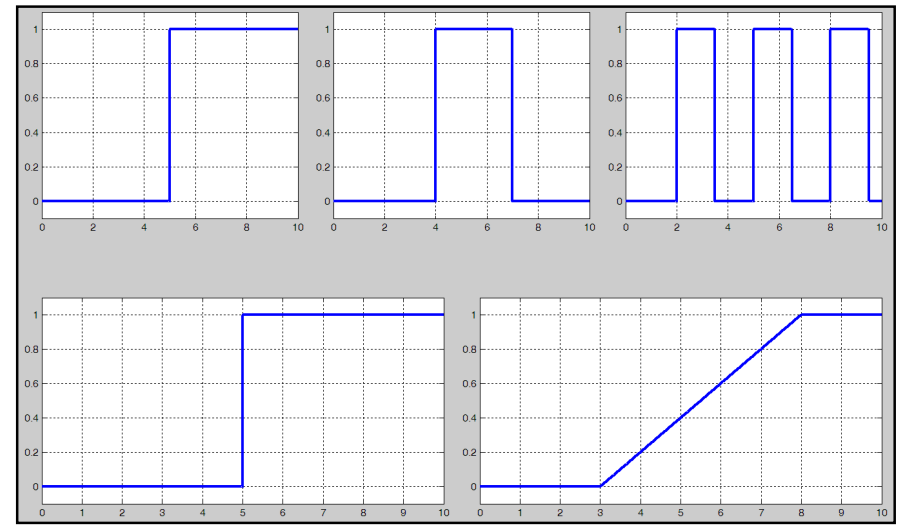

Figure 4 : fault behaviors

Fig. 4 shows graphical representations of all kind of behaviors. The $y$-axis represents the presence of the fault: from 0 for an absence to 1 for a total presence. The first graph (top and left) represents a permanent fault starting at time 5; the second graph (top and middle) represents a transient faults starting at time 5 and stopping at time 7; and the third graph (top and right) represents an intermittent faults starting at time 2 with a period of 3 times and a percentage of fault presence equal to $50 \%$. The fourth graph (bottom and left) represents an abrupt appearance and the fifth graph (bottom an right) represents a progressive appearance starting at time 3 with a slope equal to 0.2 .

\section{2) Fault effects}

The effect represents the location on the system and its disturbance. In [4], [5] and [3], different fault locations can be established in the system. There are sensor faults, actuator faults, faults in the process and faults in the controller. For our subject, faults in the FCS, faults in the controller are not considered. If we consider a system described by the equation (1), where dynamic is ignored:

$$
y(t)=g(x(t), \theta, u(t))
$$

a sensor fault will disturb the output vector $y$, an actuator fault will disturb the input vector $u$ and fault in the process will disturb the state vector $x$ or the parameter vector $\theta$. By considering a variable $v$ (the input $u$ or the output $y$ or the state $x$ or the parameter $\theta$ ), its disturbed value, noted $v_{F}$, is then equal to :

$$
v_{F}(t)=\operatorname{Dist}_{v_{F}}(t, v(t), f l t(t))
$$

where $f l t(t)$ is the fault behavior.

The kind of disturbance can be additive, multiplicative, sinusoidal or limitative. For an additive disturbance, equation (2) is then :

$$
v_{F}(t)=v(t)+a \cdot f l t(t)
$$

where $a$ is the additive parameter. For a multiplicative disturbance, equation (2) is then :

$$
v_{F}(t)=v(t) \cdot(1+m \cdot f l t(t)-f l t(t))
$$

where $m$ is the multiplicative parameter. For a sinusoidal disturbance, equation (2) is then : 


$$
v_{F}(t)=v(t)+f l t(t) \cdot(a \cdot \operatorname{Sin}(f \cdot t))
$$

where $a$ is the amplitude parameter and $f$ is the frequency parameter (rad/time). For a limitative disturbance, equation (2) is then :

$$
v_{F}(t)=\left\{\begin{array}{l}
v_{\max }, \text { if } v(t)>v_{\max } \text { and } f l t(t)>0 \\
v_{\min }, \text { if } v(t)<v_{\min } \text { and } f l t(t)>0 \\
v(t), \text { if }\left[v_{\min }<v(t)<v_{\max } \text { and } f l t(t)>0\right] \text { or } f l t(t)=0
\end{array}\right.
$$

where $v_{\max }$ is the maximum parameter and $v_{\min }$ is the minimum parameter.

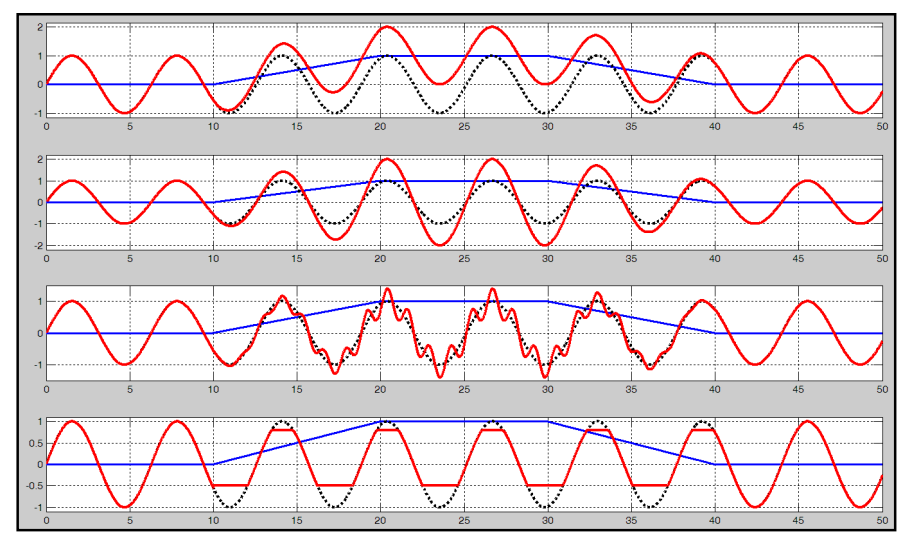

Figure 5 : fault disturbances

Fig. 5 shows graphical representations of all kinds of disturbances. The fault behavior (plain right line) is a progressive transient one, starting at time 10, stopping at time 30 and with a slope equal to 0.1 . The initial variable (dot curve line) is a sinusoidal one with amplitude equal to 1 and a frequency equal to $1 \mathrm{rad} / \mathrm{time}$. The disturbed variable is represents by the plain curve line. The first graph shows an additive disturbance with an additive parameter equal to 1 . The second graph shows a multiplicative disturbance with a multiplicative parameter equal to 2 . The third graph shows a sinusoidal disturbance with an amplitude parameter equal to 0.2 and a frequency parameter equal to $5 \mathrm{rad} / \mathrm{time}$. The fourth graph shows a limitative disturbance with a minimum parameter equal to -0.5 and a maximum parameter equal to 0.8 .

\section{The fault library}

Faults are added in the model, by a library, according to the classification described before. This kind of representation, by separating the fault behavior and the fault effect, was taken into account to construct the fault library-which is composed by two blocs. The 'fault-signal-bloc', representing fault behaviors, emits a signal between 0 (absence of the fault) and 1 (total presence of the fault) with parameters to define all possible behaviors. The 'perturbation-bloc', representing fault effects, perturbs a signal (an input $u$ or an output $y$ or a state $x$ or a parameter $\theta$ ), according to affected components and depending to the 'fault-signal-bloc'.

This library is well adapted for systems modeled by assembling various components. Firstly, even if a fault perturbs many components, only one 'fault-signal-bloc' is required to characterize its behavior. Secondly, all possible faults of a component can be integrating by adding a 'perturbation-bloc' directly in the component; an input port is also added in the component to control the 'perturbation-bloc' by a 'faultsignal-bloc'. It is particularly interesting when components are reused.

\section{Faults integration in the fuel cell system model}

The fault library was used to integrate faults in the FCSM. We have performed three kinds of integration:

- For the first kind of integration, we just have inserted the 'perturbation-bloc' and the 'fault-signal-bloc' in a link of two components. For an input fault, the 'perturbation-bloc' is integrated in the link just before the faulty component; whereas for output fault, it is integrated in the link just after the faulty component. For example, the lock of the air compressor; decreases abruptly to 0 the air mass flow rate; and during the fault presence, the air mass flow rate is equal to 0 for any compressor orders. The 'perturbation-bloc' is then integrated just after the compressor output port to the air line and the 'fault-signal-bloc' is linked to this 'perturbation-bloc' (Fig. 6).

- For the second kind of integration, we have had to enter in the component to directly link the 'perturbation-bloc' with a variable parameter or a state. We have added a new input port to the component to control this 'perturbation-bloc' with a 'fault-signal-bloc'. For example, a dirtying of a valve is represented by a reduction of the valve section; the perturbation-bloc' is linked to this section parameter directly in the component.

- For the third kind of integration, we have added a new actuator controlled by a 'fault-signal-bloc' and some physical components. For example, a leak of hydrogen is represented by a hole in the pipe line:; we have added a valve, controlled by a 'fault-signal-bloc', and a pipe to represent the hole.

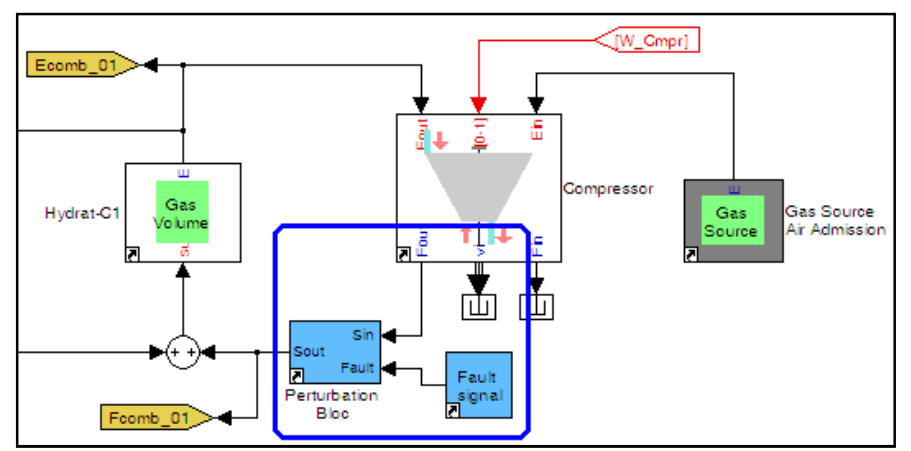

Figure 6 : fault affecting the air line compressor

\section{FAUlty and FAUltLess BeHaVioral ModELS}

By adding faults in the FCSM, we have produced all faulty models requested for the MBDy study. In order to make them usable for this MBDy study, we must have to consider, in faultless and all faulty cases, observable behaviors of the FCSM with its controller. In fact, the diagnosis system has only access to observable data: orders from controllers and data from sensors. For the FCSM, these observable variables are electrical power orders from the vehicle controller, air mass flow rate and air and hydrogen pressures orders from the global 
FCS, compressor and valves orders from the two line controllers and data measured by sensors: air mass flow rate and air and hydrogen pressures stack voltage and current (to compute the electrical power).

In the two following figures, we show observable behaviors of the FCSM: a faultless one (Fig. 7) and a faulty one (Fig. 8). The electrical power, ordered from the vehicle controller to the FCS controller, is a random function like a city use: when the conductor speeds up and brakes and speeds up again but stronger and so on.

In these two figures, the first graph represents the electrical power; the dot line is orders from the vehicle controller and the plain line is estimated measures from sensors. The second, third and fourth graphs represent air line observable variables. The air mass flow rate and air pressure, regulated by the air line controller, are showed in the second and third graphs with orders from the FCS controller in dot line and measures from sensors in plain line. The fourth graph shows compressor orders in plain line and valve orders in dot line. The fifth and sixth graphs represent hydrogen line observable variables. The hydrogen pressure, regulated by the hydrogen line, is showed in the fifth graph with orders from the FCS controller in dot line and measures from sensors in plain line. The sixth graph shows admission valve orders in plain line and rejection valve orders in dot line.

\section{A. Faultless behavioral model}

Fig. 7 shows a faultless behavior of the FCSM. For increasing or decreasing electrical power orders (first graph), not only the time response is complied with requirements (between 1.5 and $2.5 \mathrm{sec}$.) but also estimated electrical power measures follow orders except for low ones: the compressor cannot be stopped for each low orders (because of consumption requirements) and then it runs at low speed and the system produces an irreducible minimal electrical power.

For the air line: the air mass flow rate (second graph) follows correctly its orders and the air pressure (third graph) follows approximately its orders because even if this pressure is controlled by the valve, it is also influenced by compressor actions (fourth graph). There is a gain relation between air mass flow rate and compressor orders: in fact, this air mass flow rate is only produced by the compressor and by increasing or decreasing the compressor speed (control by compressor orders) the mass flow rate increases or decreases following this compressor speed. The valve controls the air pressure, but as said before, this pressure is also influenced by compressor actions and therefore the relation between this valve control and air pressure is more complex.

For the hydrogen line: the hydrogen pressure (fifth graph) follows particularly correctly its orders; orders directly provided by air pressure measures. The exhaust valve is always closed and the pressure is only controlled by the admission valve (sixth).

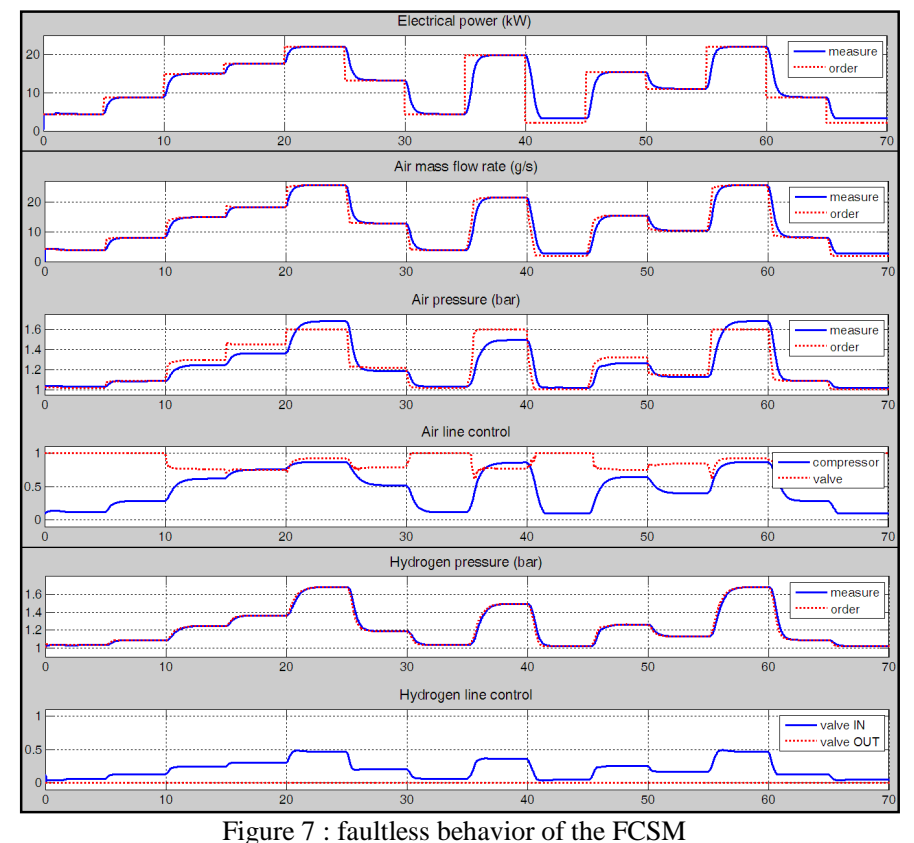

\section{B. Faulty behavioral model}

Fig. 8 shows a faulty behavior of the FCSM for the same electrical power orders than the faultless case (first graph). The fault is a lock of the air compressor. We have parameterized this fault with an abrupt apparition during the time interval $[38 ; 48]$. During the faultless time, the FCSM operates correctly, as the faultless behavior; but during the faulty time apparition, we can see disturbances in all graphs

In the first graph, during the faulty time apparition, estimated electrical power measures decreases abruptly and highly to $0 \mathrm{~kW}$ : in fact the fault concerns the compressor, the air mass flow rate (second graph) decreases abruptly and highly to $0 \mathrm{~g} / \mathrm{s}$ and the air line controller informs the FCS controller that it can't produce the air mass flow rate needed, then the FCS controller estimates electrical power measures to $0 \mathrm{~kW}$ and request air mass flow rate equal to $0 \mathrm{~g} / \mathrm{s}$ and air pressure equal to 1 bar (no pressure).

Compressor orders (fourth graph) are therefore maximums (equal to 1) in order to compensate the difference between orders and measures; air pressure measures are also equals to 1 bar.

Hydrogen pressure orders (fifth graph) are then equal to 1 bar because they are air pressure measures; hydrogen pressures measures decreases slowly because in spite of exhaust valve orders are maximums (sixth graph), its sections is too small to exhaust hydrogen in high time (because of safety requirements with hydrogen use). 


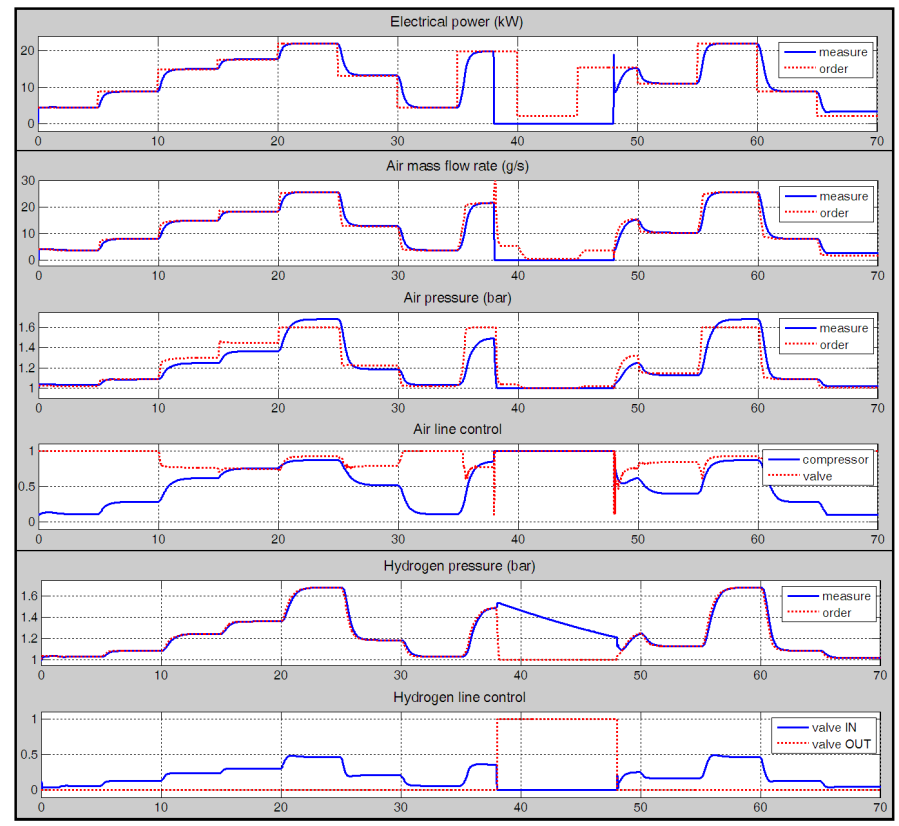

Figure 8 : faulty behavior of the FCSM

\section{Analysis and result for future works}

Fig. 7 and Fig. 8 show observable behaviors generated by the faultless model and a faulty model. By comparing them we observe a significant difference: during the presence of the fault, evolutions of observable variables of the faulty model are strongly different to observable variables of the faultless model.

Such a study of the difference between two models can be used in the context of MBDy. According to the same orders, if there is no difference between observable behaviors generated by two models (the faultless and a faulty, or two faulty), the fault will then be said un-diagnosable. Indeed, according to the MBD approach (see [3] and [5] for full explanations of MBD methodology), the embedded diagnosis system will not be able either to detect the fault when it occurs or to assign a unique listed fault to the divergent observable behavior.

\section{CONCLUSIONS AND PERSPECTIVES}

In this paper, our goal was to improve a model of an embedded fuel cell system in order to make it usable for the model-based diagnosability study of faults. We have first presented the fuel cell system with its controller and its model. Then, we have exposed the principle and components of the fault library, where fault behavior and fault effect are clearly separated. Thanks to this library, we have improved the model of the fuel cell system with faults. Our interest was focused on faults affecting the fuel cell stack integrity and faults related to the hydrogen line. The main result of this paper is therefore the fault library. It was used to improve the model of the fuel cell system and prepare it for the model-based diagnosability study.

We have also begun the analysis of some observable behaviors of the model in the faultless and faulty cases which reveal significant differences. In future works, these observable behaviors will be used to generate characterization of faults for the diagnosability study. These fault characterizations will also be embedded by the diagnosis system in order to detect and identify faults. These future works will be presented in forthcoming papers.

\section{REFERENCES}

[1] F. Roy, S. Garnit, and J. P. Poirot Crouvezier, "Fisypac project : The first vehicle integration of genepac fuel cell stack", In The International Electric Vehicle Symposium and Exposition (EVS 24), 2009

[2] R. F. Stapelberg, "Handbook of Reliability, Availability, Maintainability and Safety in Engineering Design", Springer-Verlag, London, 2009.

[3] R. Isermann, "Fault Diagnosis Systems", Springer-Verlag, Berlin, 2006.

[4] M. Basseville, "On fault detectability and isolability", Research Report IRISA no 1240, 1999.

[5] M. Blanke, M. Kinnaert, J. Lunze, and M. Staroswiecki, "Diagnosis and Fault-Tolerant Control", Springer-Verlag, Berlin, 2006.

[6] R. Isermann, "Supervision, fault-detection and fault-diagnosis methods - An introduction", in Control Engineering Practice, Volume 5, Issue 5, May 1997, Pages 639-652, 2006

[7] R. F. Mann, J. C. Amphlett, M. A. I. Hooper, H. M. Jensen, B. A. Peppley, and P. R. Roberge, "Development and application of a generalized steady-state electrochemical model for a PEM fuel cell", in Journal of Power Sources, vol. 86, pp. 173-180, 2000.

[8] P. Famouri, P. and R.S. Gemmen, "Electrochemical circuit model of a PEM fuel cell", in Proc. 2003 IEEE Power Engineering Society General Meeting, vol. 3, 13-17 July 2003.

[9] J. H. Lee, T. R. Lalk, and A. J. Appleby, "Modeling electrochemical performance in large scale proton exchange membrane fuel cell stacks", in Journal of Power Sources, vol. 70, pp. 258-268, 1998.

[10] J. T. Pukrushpan, H. Peng, and A. G. Stefanopoulou, "Simulation and analysis of transient fuel cell system performance based on a dynamic reactant flow model", in Proc. 2002 ASME International Mechanical Engineering Congress \& Exposition, IMECE, Nov. 17-22, 2002.

[11] C. Wang, M. H. Nehrir, and S. R. Shaw, "Dynamic models and model validation for PEM fuel cells using electrical circuits", in IEEE Trans. Energy Conversion, vol. 20, issue 2, pp. 442 - 451, June 2005.

[12] J. T. Pukrushpan, A. G. Stefanopoulou, and H. Peng, "Modeling and control for PEM fuel cell stack system", in Proc. American Control Conference, Anchorage, AK, May 8-10, 2002.

[13] J. Garnier, M. C. Pera, D. Hissel, F. Harel, D. Candusso, N. Glandut, J. P. Diard, A. D. Bernardinis, J. M. Kauffmann, and G. Coquery, "Dynamic PEM fuel cell modeling for automotive applications", in Proc. IEEE 58th 2003 Vehicular Technology Conference, vol. 5, 6-9 Oct. 2003, pp. 3284 - 3288.

[14] A. Ingimundarson, A. Stefanopoulou, and D. A. McKay, "Model-based detection of hydrogen leaks in a fuel cell stack", in IEEE Transactions on Control Systems Technology, 16(5):1004-1012, Sept. 2008

[15] M. Arcak, H. Grgn, L. M. Pedersen, and S. Varigonda, "A nonlinear observer design for fuel cell hydrogen estimation", in IEEE Transaction on Control System Technology, vol. 12, pp. 101-110, 2004.

[16] J. Pukrushpan, A. Stefanopoulou, and H. Peng, "Control of natural gas catalytic partial oxidation for hydrogen generation in fuel cell aplications", in IEEE Transactions on Control Systems Technology, vol. 13, pp. 3-14, 2005.

[17] J. Alcock, L. Shirvill, and R. Cracknell, "Compilation of existing safety data on hydrogen and comparative fuels", Shell Global Solutions, Tech. Rep., May 2001.

[18] J. Brunet, L. Flambard and A. Yazman, "A Hardware in the Loop (HIL) Model Development and Implementation Methodology and Support Tools for Testing and Validating Car Engine Electronic Control Unit (ECU)", in The International Conferences on CAE and Computational Technologies for Industry. (TCN CAE), 5-8 Oct, 2005. 